Enrique C. Papa II, MD Emmanuel S. Samson, MD

Francisco A. Victoria, MD

Department of Otorhinolaryngology

Head and Neck Surgery

Ospital ng Maynila Medical Center
Correspondence: Enrique C. Papa II, MD Department of Otorhinolaryngology-Head and Neck Surgery Ospital ng Maynila Medical Center

Quirino Ave. cor. Harrison Blvd., Malate, Manila 1004 Philippines

Phone: (632) 5246061 local 220

Email: enriq9tales@yahoo.com

Reprints will not be available from the author.

No funding support was received for this study. The authors signed disclosures that they have no proprietary or financial interest with an organization that may have a direct interest in the subject matter of this manuscript or in any product used or cited in this study.

Presented at Clinical Case Report Contest (2nd Place), Philippine Society of Otolaryngology- Head and Neck Surgery Mid-year Convention, Bohol Tropics Hotel, Bohol, Philippines April 24, 2009.

\section{Cavernous Hemangioma of the Mandible}

\section{ABSTRACT}

Objectives: To report a case of hemangioma arising from the mandible and its clinical presentation; describe the similarities with which mandibular hemangioma may mimic odontogenic and non-odontogenic lesions; and identify diagnostic and treatment modalities employed in these patients.

\section{Methods:}

\author{
Design: Case Report \\ Setting: Tertiary Public Hospital \\ Patient: One
}

Results: A 12-year-old male with intractable gum bleeding exacerbated by intraoperative manipulation of a loose first premolar and uncontrolled by left external carotid ligation, underwent segmental mandibulectomy. The resected segment revealed multiple porosities and a hollow blood-filled cavity. Histopathology confirmed the diagnosis of cavernous hemangioma.

Conclusion: Though rare, mandibular hemangiomas should be considered in lesions involving the mandible. Diagnosis is difficult with an array of lesions that may appear clinically and radiographically similar. The non-specific signs and symptoms of mandibular hemangioma could lead to exsanguinating hemorrhage if not attended to promptly.

Keywords: cavernous hemangioma, mandible, hemorrhage, external carotid ligation, mandibulectomy 
While simple gum bleeding is seldom taken seriously, massive, pulsating gingival hemorrhage is often dramatic and may be fatal. Precipitated by a simple dental extraction or more violent forms of trauma, control of massive hemorrhage may be troublesome for the clinician, particularly when the underlying cause is unknown or involves multiple unlikely differential diagnoses. We report the case of a benign mandibular lesion that warranted an aggressive approach due to potentially fatal exsanguination.

\section{CASE REPORT}

A 12-year-old male was referred for intractable left lower gingival bleeding which began over a period of two months. The boy was received biting into an oral pack secured with Barton's bandage and was slightly jaundiced with pale nail beds and hemoglobin of $8 \mathrm{mg} / \mathrm{dL}$. He weighed 14 kilograms and had 4 units of packed red blood cells transfused prior to transfer. There was no gross deformity in the area of the left mandible which was not manipulated following the advice of the referring physician not to remove the oral pack as profuse bleeding could ensue from what was likely a hemangioma of the mandible. A similar bleeding episode six years before had been managed with a right mandibulectomy in another hospital.

Radiographs showed surgical discontinuity of the right mandible and a radiolucency in the left mandible (Figure 1). Intraoperatively, profuse bleeding squirted from the lingual surface of the mandible adjacent to the first molar following oral pack removal. The first and second premolars were loose. Extraction of the first molar caused massive bleeding from the socket, uncontrolled by external carotid artery ligation, necessitating tamponade with antibiotic-impregnated gauze sutured into place and tracheostomy. Another 4 units of packed red blood cells plus two units of fresh whole blood had to be transfused.

A post-operative panoramic radiograph clearly revealed a $5 \times 3$ $\mathrm{cm}$ radiolucent area in the body of the left mandible (Figure 2) and a segmental mandibulectomy was performed with profuse bleeding that only stopped after final release of the proximal periosteum. The $3 \mathrm{~cm}$. resected segment was hollow with multiple porosities extending to the symphyseal area (Figure 3). Histopathologic microsections revealed viable bone spicules interspersed with fibrous areas and vessels with wide lumina filled with red blood cells confirming the diagnosis of cavernous hemangioma (Figure 4).

\section{DISCUSSION}

Hemangiomas occurring in soft tissues are common and easily diagnosed through clinical data alone. Hemangiomas occurring in bones are rare, accounting for only $0.7 \%$ of all osseous neoplasms and $10 \%$ of primary benign neoplasms occurring in the skull.' In the mandible, the tumor has a female: male predominance of 3:1 and occurs most frequently in the portion of the body although condylar tumors have also been cited. $^{2}$

Differential diagnoses included hemangiopericytomas, arterio-venous (AV) malformations and aneurysmal bone cysts. Hemangiopericytomas usually present with rapid growth and non-painful gingival swelling. ${ }^{3}$ AV malformations have a predilection for age groups in the mixed dentition period and are associated with spontaneous bleeding but typically present with a bruit or evident pulsation. ${ }^{4}$ Aneurysmal bone cysts (ABC) also have rapid growth and gingival swelling but involve pain from expansion of the bony cortex.

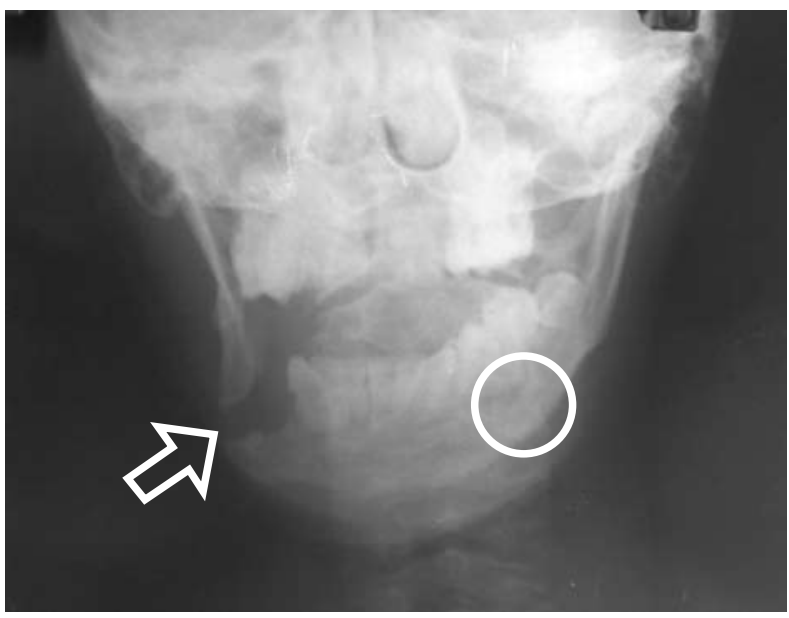

Figure 1. Skull AP/L showing discontinuity of the right mandibular body (arrow) and suspicious radiolucency in the left (circle).

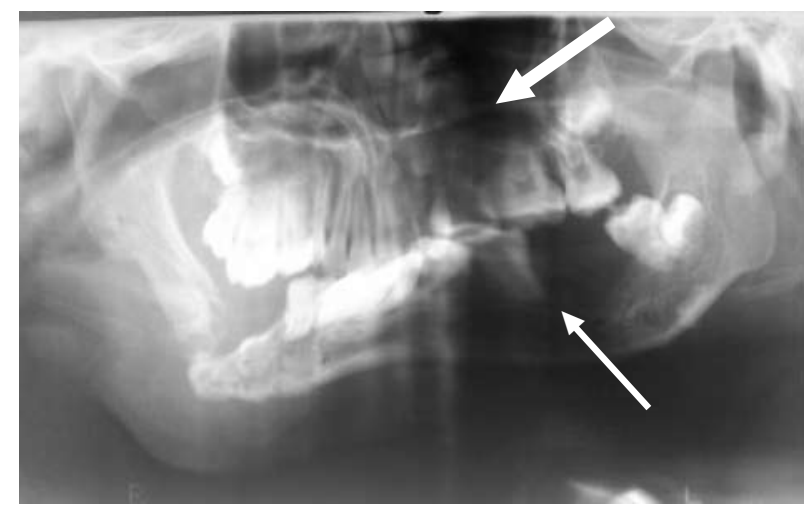

Figure 2. Panoramic radiograph showing radiolucency in the body of the mandible (arrow) 
The non-painful intractable bleeding being the sole symptom presented in the case made its initial diagnosis complicated since it resembles many odontogenic and non-odontogenic tumors. Other symptoms that are non-specific but may otherwise narrow the diagnosis include mobility of the adjacent teeth, derangement of occlusion, non-painful bony swelling and pain, when present maybe the only reason for patients to consult. ${ }^{4}$

Khanna et al reported cases of a clinically-diagnosed ameloblastoma in a 14-year-old male with painless swelling of the right jaw and a 46-year-old male with bleeding gums and a loose lower premolar tooth where resections both revealed cavernous hemangioma. ${ }^{5}$ Mardwah et al. reported an 8-year-old male who underwent dental extraction which progressively led to swelling also due to hemangioma. ${ }^{6}$

Although angiography is the cornerstone for diagnosis of vascular lesions, ${ }^{4}$ this option was pre-empted by the additional blood loss the added time delay would entail as well as the financial constraints of our indigent patient. This eliminated the option for preoperative embolization as well. Other options including radiation and intralesional sclerosing agents have only limited applications in cases of soft tissue involvement since their intraosseous effects remain doubtful. ${ }^{6}$ Radiography, being easily accessible, is an important ancillary tool for evaluation of mandibular lesions. However, radiolucencies seen on plain film and panoramic radiographs suggest a variety of mandibular lesions that may need further CT and MRI workups but these were beyond the resources of our patient.

The greatest hazard in this case is exsanguinating hemorrhage which may be fatal as reported by Lamberg ${ }^{7}$ or near-fatal as in the case of Sadain-Urao. ${ }^{8}$ Control of hemorrhage is crucial and restoring hemodynamic stability vital. The cessation of bleeding upon periosteal release and multiple porosities of the mandibular body suggest a peripheral hemangioma which originates in the periosteic vessels that grow into the medullar bone (unlike central hemangiomas that originate in the medullar bone and grow towards the cortical bone). ${ }^{5}$ As in our case, the most frequent location of hemangioma of the mandible is the molar-premolar region. ${ }^{5}$ Histopathologic study is helpful in confirming the diagnosis. The microscopic picture is that of a proliferating mass of endothelial cells forming a plexiform arrangement of vascular spaces which can either be capillary, cavernous or mixed. ${ }^{6}$

Though rare, mandibular hemangiomas should be considered in lesions involving the mandible. Diagnosis is difficult with an array of lesions that may appear clinically and radiographically similar. The non-specific signs and symptoms of mandibular hemangioma could lead to exsanguinating hemorrhage if no appropriate intervention is performed.
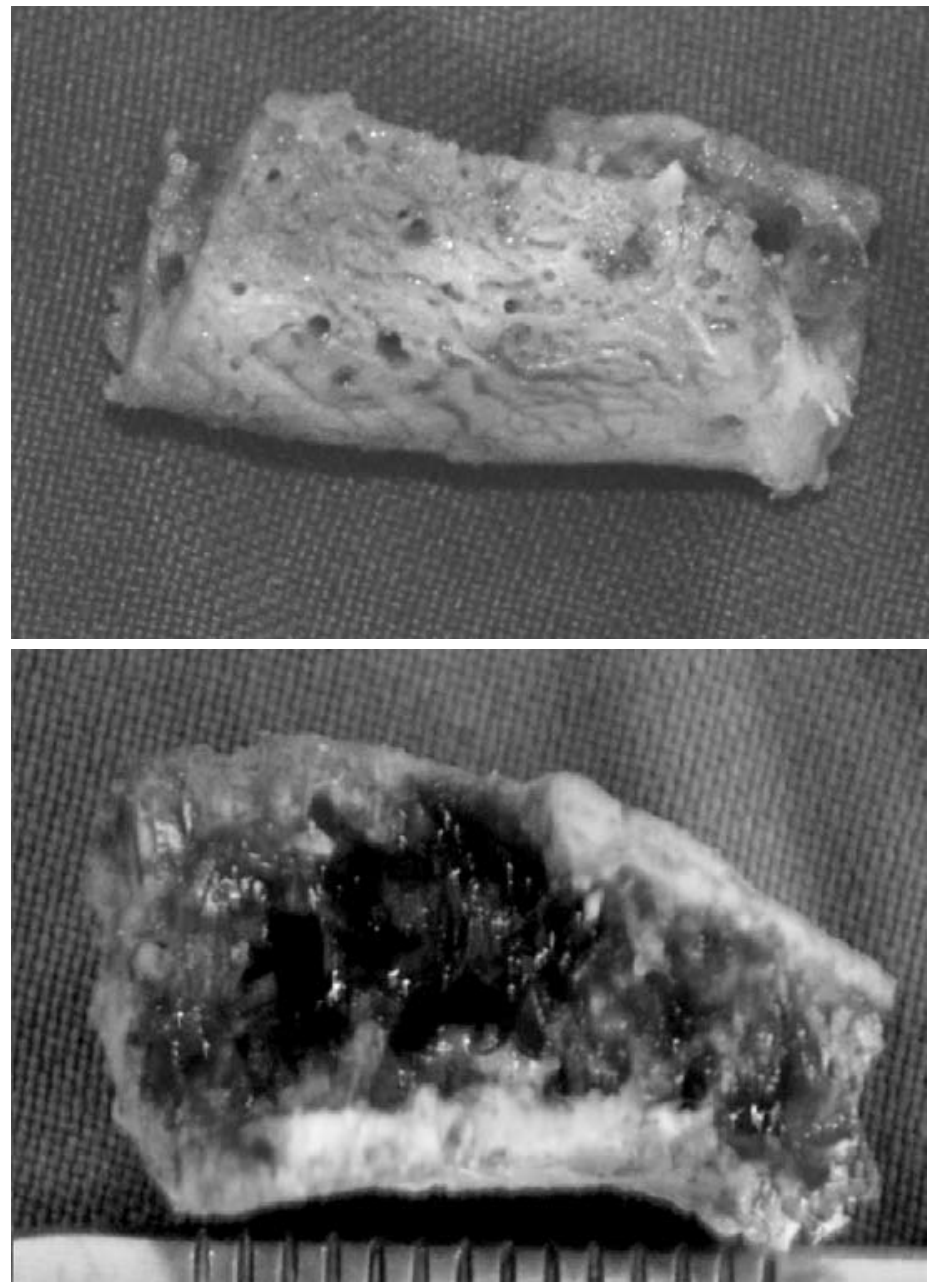

Figure 3. (Top photo) $3 \mathrm{~cm}$ resected mandibular segment from parasymphysis to the symphysis, showing a hollow cavity filled with blood and multiple porosities 
CASE REPORTS

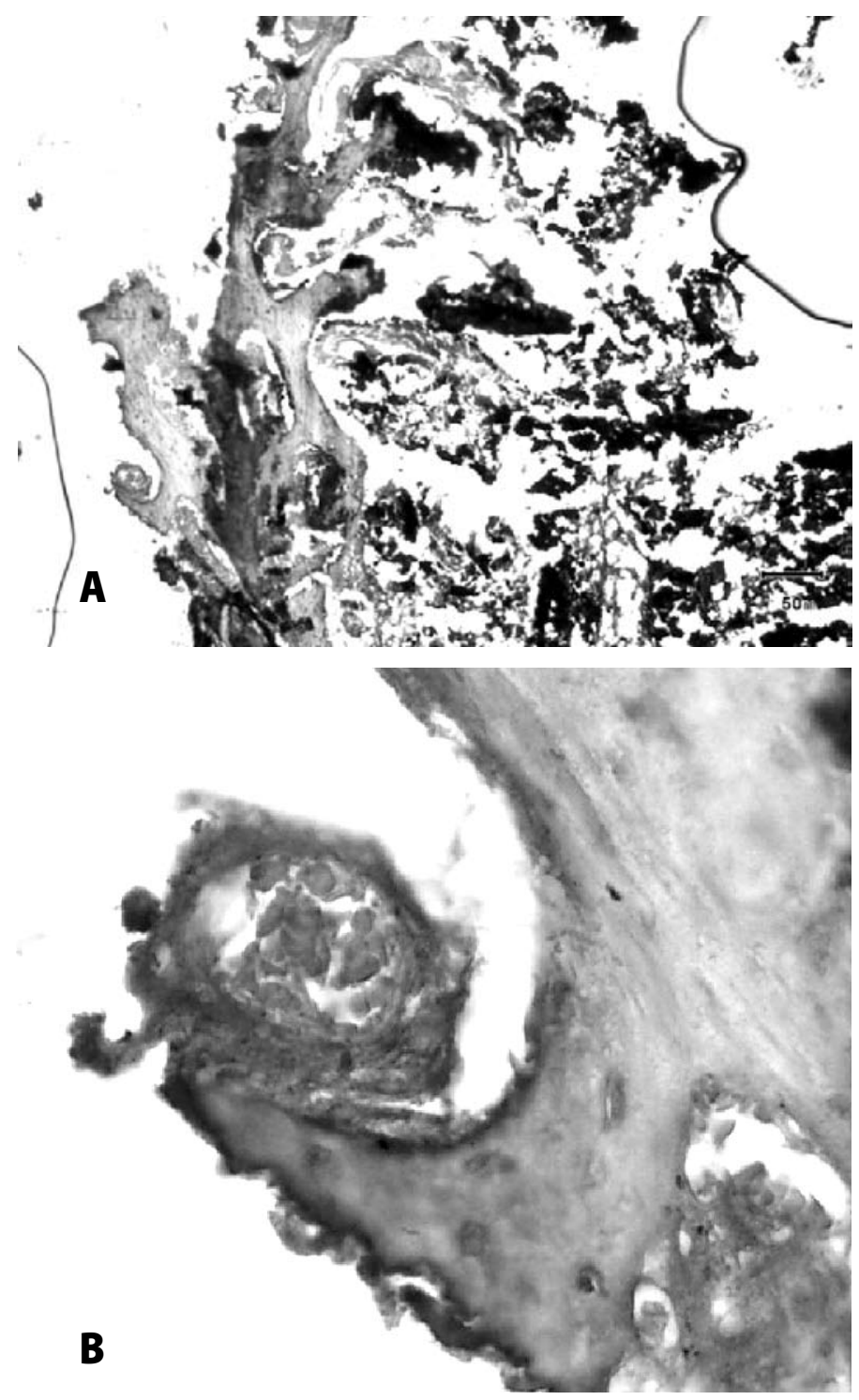

Figure 4. Pictomicrograph showing large blood vessels filled with red blood cells interspersed within viable bone spicules. A, low power (Hematoxylin-Eosin, LPO,100x) B, high power (Hematoxylin-Eosin, HPO, 400x)

\section{REFERENCES}

1. Batsakis JG. Tumors of the Head and Neck. $2^{\text {nd }}$ Ed, Baltimore: Williams and Wilkins; 1979.

2. Neyaz Z, Gagodia A, Gamanagatti S, Mukhopadhyay S. Radiographical approach to jaw lesions. Singapore Med J. 2008 Feb; 49(2):165-76.

3. Bhutia O, Roychudry A. Hemangiopericytoma of the Mandible. J Oral Maxillofac Pathol 2008;12:26-8

4. Menon L; Chowhudry R, Mohan C. Arteriovenous Malformation in Mandible. MJAFI. $2005 ; 61(3)$.

5. Khanna, P.R. , Khanna A.K. , Kumarl Mohan. Hemangioma of the Mandible: Clinical Report. Indian J.ORL-HNS. 2004 Apr-Jun; 56 (2).

6. Mardwah N, Agnihotri A, Dutta S. Central Hemangioma: A Overview and Case Report; Pediaty. Dent. 2006 Sep-Oct; 28(5): 460-6.

7. Lamberg MA, Tasanen A, Jääskeläinen J. Fatality from central hemangioma of the mandible. J Oral Surg 1979; 37(8):578-84 1979 Aug; 37(8):578-84.

8. Sadain-Urao ZK, Pontejos AQY. Hemangioma of the Mandible: An exsanguinating lesion. Philipp J Otolaryngol Head Neck Surg. 1998. 21-26

9. Cummings CW, Flint PW, Haughey BH, Robbins KT, Thomas JR, Harker LA Otorhinolaryngology Head and Neck Surgery $5^{\text {th }}$ Ed. Elsevier: Mosby; 2005. 